\title{
REFLEXÕES ACERCA DA MEDIAÇÃO COMUNITÁRIA COMO ESTRATÉGIA PRÁTICA DE CIDADANIA PARTICIPATIVA
}

\section{REFLECTIONS ON THE COMMUNITY MEDIATION PRACTICE A STRATEGY OF PARTICIPATORY CITIZENSHIP}

\author{
Dhieimy Quelem Waltrich* \\ Fabiana Marion Spengler*
}

SUMÁRIO: Introdução - 2 O surgimento da cidadania: do direito primitivo ao direito moderno - 3 O Locus: a comunidade - 4 A mediação comunitária como estratégia de cidadania participativa -5 Conclusões -6 Referências bibliográficas.

RESUMO: O presente artigo pretende analisar o procedimento de mediação comunitária como estratégica prática de cidadania participativa. Veremos que com base no diálogo e na mediação de conflitos é possível reconhecer a capacidade dos cidadãos de se organizarem e, com base na comunicação, construírem decisões racionais consideradas justas e legítimas por todos os envolvidos no processo de comunicação. Neste contexto, o procedimento de mediação de conflitos tem demonstrado ser ferramenta útil à construção de ambientes propícios ao diálogo ético, mostrando-se ferramenta importante para a construção de uma democracia baseada na razão comunicativa.

Palavras-chave: Mediação. Conflito. Cidadania Participativa.

ABSTRACT: This article analyzes the process of community mediation as a strategic practice of participatory citizenship. We will see that based on dialogue and conflict mediation is possible to recognize the ability of citizens to organize themselves and, based on communication, build rational decisions considered fair and legitimate by all involved in the communication process. In this context, the process of conflict mediation has proved to be useful tool to build environments conducive to ethical dialogue, proving to be an important tool to build a democracy based on communicative rationality

Keywords: Mediation. Conflict. Participatory Citizenship.

\footnotetext{
* Professora adjunta da Faculdade Anhanguera, unidade de Passo Fundo/RS, mestre pela Universidade de Santa Cruz do Sul.

Pós-Doutorado pela Università degli Studi di Roma Tre e professora da Universidade de Santa Cruz do Sul.
} 


\section{INTRODUÇÃO}

Atualmente, muito se fala sobre as formas alternativas de tratamento dos conflitos, principalmente no que diz respeito à mediação, que contribui diretamente para a construção de uma justiça mais democrática e cidadã.

É inegável que a mediação é um eficaz instrumento de pacificação social e democratização de acesso à justiça, por esse motivo, o presente artigo visa demonstrar que a cidadania participativa trata-se de uma estratégia para a formação de uma sociedade melhor, e a mediação comunitária, como ação social, diz respeito ao exercício da cidadania como processo inventivo, de forma que toda a comunidade envolvida possa fazer isso igualmente. Avançando daí para a maior democracia.

$\mathrm{O}$ direito de acesso à Justiça, previsto no art. $5^{\circ}, \mathrm{XXXV}$, da Constituição Federal além da vertente formal perante os órgãos judiciários, implica acesso à ordem jurídica justa. Assim cabe ao Judiciário estabelecer política pública de tratamento adequado dos problemas jurídicos e dos conflitos de interesses, que ocorrem em larga e crescente escala na sociedade, de forma a organizar, em âmbito nacional, não somente os serviços prestados nos processos judiciais, como também os que possam sê-lo mediante outros mecanismos de solução de conflitos, em especial dos consensuais, como a mediação e a conciliação.

Considerando, portanto, a necessidade de se consolidar uma política pública permanente de incentivo e aperfeiçoamento dos mecanismos consensuais de solução de litígios, foi sendo sedimentado o entendimento de que a conciliação e a mediação são instrumentos efetivos de pacificação social, solução e prevenção de litígios, e que a sua apropriada disciplina em programas já implementados no país tem reduzido à excessiva judicialização dos conflitos de interesses, a quantidade de recursos e de execução de sentenças.

Os novos métodos consensuais de resolução dos conflitos são modelos de interação social que fogem daquele modelo impositivo, antagônico e dão espaço para o vínculo participativo, dialógico e cooperativo, que caracteriza um dos pressupostos básicos para a existência da cidadania - o de que os sujeitos ajam e lutem por seus direitos -, momento em que é devolvido a comunidade o poder de decisão de conflitos que ocorreram em seu seio.

O que se pretende é repensar a jurisdição num sentido mais amplo, haja vista que o conflito assume uma dinâmica negativa que deixa 
de conduzir ao crescimento, e que deflagra a necessidade de procedimentos eficientes para tratá-lo.

Diante disso, a reflexão proposta visa defender o modelo da ação orientada ao entendimento, sendo que o entendimento recíproco é fundamental, haja vista que a atitude dos participantes na interação que coordenam visa o entendimento entre si, assim, essa condição implica que não se tenha atração pelo autoritarismo como forma rápida de solucionar o litígio. Embora custoso e mais lento, o processo democrático é mais seguro em seu caminho de preservar e melhorar as condições da vida humana, com a participação de todos.

O método de abordagem a ser utilizado será o hipotéticodedutivo, haja vista tratar de questões que exigem experimentação e construção de conjecturas, que devem ser submetidas a testes, os mais diversos possíveis, à crítica intersubjetiva, ao controle mútuo pela discussão crítica, à publicidade (sujeitando o assunto a novas críticas) e ao confronto com os fatos, para verificar quais são as hipóteses que persistem como válidas resistindo às tentativas de falseamento, sem o que seriam refutadas. É um método de tentativas e eliminação de erros, que não leva à certeza, pois o conhecimento absolutamente certo e demonstrável não é alcançado.

O método de procedimento será o histórico, haja vista a necessidade de resgate dos ensinamentos jurídicos de diversos doutrinadores e aplicadores do direito.

\section{O SURGIMENTO DA CIDADANIA: DO DIREITO PRIMITIVO AO DIREITO MODERNO}

Nas sociedades primitivas, onde a vontade divina era interpretada e os usos e costumes predominavam, ainda não existia um conceito de normas objetivas, isto é, não existia uma lei objetiva independente das ações. Isso somente ocorreu com o surgimento do direito tradicional.

No direito tradicional, a lei é imposta por poderes seculares ou teocráticos. As normas são tomadas como dadas, como convenções transmitidas pela tradição. As ações são julgadas à luz de normas legais tradicionais. O direito tradicional, evidentemente, permanece particularista: não está ainda baseado em princípios legais universalistas. Isto será alcançado pelo direito natural, ao admitir que os 
princípios podem ser alcançados racionalmente. (VIEIRA, 2002, p. 16).

O Direito Moderno baseado em princípios, na lei e na administração especializada da justiça é inaugurado pelo direito natural, no qual as normas são promulgadas segundo princípios estabelecidos livremente por acordos racionais.

Diante disso, o direito natural, com base no Contrato Social - os indivíduos, em princípio livres e iguais, estabelecem por contrato, um determinado modelo de elaboração e justificação das normas legais promovem a passagem do consenso tradicional para o consenso racional da modernidade.

O Jusnaturalismo foi, sem dúvida, a doutrina jurídica por detrás dos direitos do homem proclamados pelas Revoluções Francesas e Americana. O ser humano passava a ser visto como portador de direitos universais que antecediam a instituição do Estado. (...) O Direito Natural seria superior ao Direito Positivo; enquanto este último se caracterizaria pelo particularismo de sua localização no espaço e no tempo, o primeiro constituiria um padrão geral com validade universal. (VIEIRA, 2002, p. 17).

A forma como foi realizado o seguimento do direito racional universalmente válido, levou a necessidade de codificação de um sistema lógico, de forma que a visão jusnaturalista de um direito racional e sistemático passou a dar espaço ao direito codificado, não sendo para tanto posto nesta categoria aquele escrito que não esteja presente nos Códigos e na Constituição.

Lafer já disse que o fundamento do direito deixou de ser buscado na razão e passou a ser a vontade do legislador. O direito se separa da razão, e o crime, da falta moral ou religiosa. Por certo, hoje o direito é produto da história, e não mais da razão. (1991, p. 45).

No século passado o positivismo considerava o Estado como fonte central de todo o Direito, e a lei como sua única expressão, formando-se assim um sistema fechado e considerado formalmente coerente, consoante os termos da Dogmática Jurídica, “que afasta do jurídico as indagações de natureza social, econômica ou política. É a fonte da teoria pura do direito de Kelsen, onde o jurídico é definido 
pela sua pura forma, e não pelos conteúdos e valores contidos em suas normas". (VIEIRA, 2002, p. 18).

Diante da necessidade de embasar uma teoria pautada no reconhecimento das necessidades naturais que envolvem as situações conflituosas e também do estabelecimento de gerações distintas para cada grupo de direitos alcançados, Hanna Arendt (2004, p. 330) estabelece a definição de um conceito de cidadania, que nada mais é do que o direito de ter direitos.

Os direitos civis conquistados no século XVIII correspondem aos direitos individuais de liberdade, sendo que a cidadania seria composta dos direitos civis e políticos - direitos de primeira geração. Já no século $\mathrm{XX}$, a partir do movimento sindical e operário, foram conquistados os direitos de segunda geração, tidos como direitos sociais e econômicos. $\mathrm{Na}$ segunda metade do século XX surgiram os direitos de terceira geração, que são direitos que não tem o indivíduo como titular, mas grupos humanos, como o povo, a nação, as coletividades étnicas ou a própria humanidade. (BOBBIO, 2004, p. 05-09).

A teoria liberal fundamentou o seu pensamento ideológico nos direitos de primeira geração, fundamentalmente na teoria de Locke (2006, p. 22), considerando o governo para o povo e não o contrário.

Já a teoria socialista, influenciada pela teoria marxista, priorizou os direitos de segunda geração, demonstrando a falácia dos direitos formais do liberalismo. Segundo Marx, $(2003,34)$ os direitos do homem não eram universais, eram direitos históricos da classe burguesa ascendente em sua luta contra a aristocracia.

Max Webber (1964, p. 214) foi um dos maiores pensadores do processo de modernização. A importância da temática verifica-se haja vista que:

A modernização é vista aqui como processo de racionalização, de diferenciação em diversas esferas (social, econômica, política, cultural etc.) que se tornam autônomas, embora dominadas pela racionalidade instrumental-cognitiva da ciência e da tecnologia. O Direito tornado essência. É dominado também pela razão instrumental, isto é, pelo mero emprego de meios técnicos para atingir os fins. (VIEIRA, 2002, p. 34). 
Diante do pessimismo instalado pelas condutas maléficas produzidas a partir da dominação da razão instrumental, Habermas construiu um gigantesco sistema filosófico, baseado em sua teoria da ação comunicativa. (VIEIRA, 2002, p. 34).

Além da razão instrumental, haveria uma razão comunicativa, fundada na linguagem, que se expressaria na busca do consenso entre os indivíduos, por intermédio do diálogo. Essa razão comunicativa se encontra na esfera cotidiana no "mundo da vida" constituída pelos elementos da cultura, da sociedade e personalidade. Habermas tenta resgatar o potencial emancipatório da razão ao afirmar que a modernidade é um projeto inacabado. Recusa a redução da idéia de racionalidade à racionalidade prático-moral (direito) e da racionalidade estético-expressiva (arte). Para ele é necessário fazer cessar a "reificação" e a "colonização" exercida pelo "sistema" sobre o "mundo da vida" mediante a lógica dialogal da ação comunicativa. (VIEIRA, 2002, p. 36-37).

Assim, as principais correntes do pensamento político contemporâneo conferem centralidade ao papel do "direito" e da "cidadania" na construção de um Estado democrático. Nesse sentido, cumpre destacar o estudo filosófico de Habermas, para quem o direito, ancorado na "moral" e não mais na "racionalidade instrumental cognitiva da ciência", é o elemento estruturador da democracia.

Diante da necessidade de estruturação dos ditos "direitos alternativos", em função dos interesses populares a serem atingidos, essa expressão se diferenciaria do "uso alternativo do direito". Por serem àqueles, considerados um direito próprio das classes exploradas, embrião de um poder alternativo.

Spengler ilustra uma passagem importante ao processo de democratização de uma comunidade. Ela relata uma experiência isolada de mediação de conflito por uma associação de moradores numa favela do Rio de Janeiro, foi vista por Boaventura Souza Santos como um novo direito, o "Direito de Pasárgada". (SPENGLER, 2010, 98).

O direito inoficial desenvolvido nas favelas das grandes cidades brasileiras, contudo, não dispõe de instrumentos de coerção oficiais. A coerção advinda das associações de bairros é muito incipiente e quase inexistente, tratando-se 
muito mais de formas de pressão do que de coerção propriamente dita. Vem crescendo, no entanto, a utilização de ameaças e de violência como instrumentos de coerção para fins não só de tratar de litígios, mas como meio de dominação e de imposição da lei do mais forte (o chefe do tráfico de drogas, por exemplo), num modelo de direito marginal. (SPENGLER, 2010, p. 98).

Diante disso, pode-se afirmar que a Democracia não é apenas um regime político com partidos e eleições livres. É, sobretudo, uma forma de existência social. Democrática, é uma sociedade aberta, que permite sempre a criação de novos direitos.

Pode-se afirmar que cabe ao Estado democrático o papel normativo de regular as relações interindividuais, bem como as relações entre o indivíduo e o Estado. Desta forma, a cidadania, poderá cumprir um papel libertador e contribuir para a emancipação humana, abrindo novas possibilidade e portas, por onde ecoarão as vozes de todos àqueles que sempre foram silenciados.

Neste domínio, penso que a idéia central é a construção de uma justiça democrática de proximidade. As pessoas que vivem nas favelas sabem o que é uma política de proximidade. É aquele que bate à entrada e bate à saída da favela. O que precisamos é uma justiça democrática de proximidade. E há muitas iniciativas meritórias que infelizmente são pouco conhecidas, não só no estrangeiro, como também no próprio país. No novo marco institucional brasileiro salientam-se a experiência da justiça itinerante, da justiça comunitária, dos meios alternativos de resolução de litígios, da mediação, da conciliação judicial e extrajudicial, da justiça restaurativa e, sobretudo, dos juizados especiais. (SANTOS, 2007, p. 57).

Diante das construções propostas, a mediação comunitária tem um papel social de extrema importância, haja vista a premissa de que o mediador deve conduzir a sessão sem aquela contaminação ilusória que as pessoas envolvidas trazem dos fatos ${ }^{1}$.

\footnotetext{
${ }^{1}$ Neste aspecto, importante a definição por MARTÍNEZ, Alejandro Rosillo.( et.al. ). Teoria Crítica dos direitos humanos no século XXI. Porto Alegre: EDIPUCRS, 2008. (...) a idéia de liberdade deve ser considerada efetivamente em suas obras e não em sua concretização. A liberdade só existe se livre de ataques e ofensas de quaisquer ordens, e
} 
O mediador estabelece orientações que conduzem os mediandos a uma visão responsável, que permite a recuperação de suas vidas e convivência, através do diálogo orientado, lembrando que a obediência ao formalismo processual muitas das vezes conduz a ausência de entendimento entre as partes, já que os prazos processuais não são os mesmos que os emocionais; e a técnica da mediação, conduz a resolução sem embate, com mais rapidez, e, principalmente, sem dores.

Fica, pois, claro que com o declínio da cidadania tem-se a mudança no papel do Estado, aumentando, portanto, a atuação da sociedade na luta pela ordem. À medida que o Estado e o Direito legislado perdem espaço (por sua ineficiência, inaplicabilidade e lentidão), o Direito inoficial ganha forças como meio de tratamento de conflitos. "Na verdade, assiste-se a um gradativo abandono do Direito "como ele é", para se atribuir valor a um novo Direito, oficialmente não legislado". (SPENGLER, 2010, p. 93).

Cada vez mais se assiste à proliferação de direitos ditos "inoficiais" que têm origem, quase sempre, na falta de atenção do Estado para com os direitos fundamentais do cidadão. Então, "adquirem legitimidade os sujeitos sociais que, por sua ação libertadora, edificam uma nova cultura societária de base, cujo direitos insurgentes são a expressão mais autêntica da satisfação das carências e das necessidades humanas fundamentais", entretanto, os critérios que compõem a legitimidade desses novos atores têm certos limites: está se falando daquela legitimidade que se constitui a partir de um conteúdo intencional, justo e programático, articulado não por quaisquer movimentos coletivos, mas somente por aqueles comprometidos com as mudanças paradigmáticas, com a pluralidade das formas de vida cotidiana e com o projeto de uma sociedade autogestionária, descentralizada, liberta e igualitária. (SPENGLER, 2010, 94-95).

Eis a razão para que o cidadão comum busque outras instâncias de tratamento de conflitos, alternativas ao Direito legislado e ao Poder Judiciário; a mediação comunitária é uma delas, e tem como alvo àqueles comunidades excluídas socialmente, na medida em que ela busca a

indubitavelmente existe, quando percebemos como instituição defensora da ética, do agir humano, independentemente de toda e qualquer obra da causalidade. 
inclusão social como uma das dimensões da efetivação dos direitos fundamentais.

\section{O LOCUS: A COMUNIDADE}

É sabido que a humanidade aspira uma sociedade que não seja unicamente uma sociedade civil, senão que chegue a ser uma boa sociedade. Diante disso, deve-se reconhecer que em uma sociedade onde nada é desrespeitado, e se trata todos com idêntico respeito, todos somos capazes de alcançar o mais completo potencial humano.

${ }^{2}$ Diz-se com freqüência que o conceito de comunidade é vago e equívoco, ocorre que as comunidades têm sido frequientemente menosprezadas como fator social de importância, mas pendente de conseguir um equilíbrio entre o estado e o mercado.

Spengler ao tecer considerações acerca dos efeitos da vivência em comunidade diz que "independentemente e não obstante as alterações/interpretativas do significado da palavra "comunidade", sem sombra de dúvida é bom "ter uma comunidade" ou "estar numa comunidade". (2011, p. 178).

Cultivar as comunidades existentes e ajudar a formar as novas aonde foram esquecidas, é essencial para o fornecimento futuro de grande parte dos bens sociais. Para promover as comunidades, os chefes de governo devem pedir aos seus ministros que lhe facilitem informes anuais sobre como comprometer mais as comunidades em seus trabalhos.

Uma boa sociedade se sustenta melhor em base de organização de serviços mútuos e a renovação comunitária pode ser facilitada se for proporcionado o intercâmbio social.

Ademais, para o florescimento das comunidades, as políticas públicas devem ter em conta muitas vezes que os limites geográficos das comunidades não correspondem com os limites administrativos. (ETZIONI, 2001, p. 39).

As políticas que pretendem renovar e apoiar as comunidades devem ter presente que estas só se fortalecem, sobretudo, nos espaços

\footnotetext{
2 Entendiendo que una buena sociedad es aquella en la que las personas se tratan mutuamente como fines en sí mismas y no como meros instrumentos; corno totalidades Iersonales y no como fragmentos; como miembros de una comunidad, unidos por lazos de afecto y compromiso mutuo, y no sólo como empleados, comerciantes, consumidores o, incluso, conciudadanos. (ETZIONI, 2001, p. 15.)
} 
públicos e não na intimidade da casa própria e do próprio veículo. Portanto, as culturas morais das comunidades são um recurso básico para edificar a boa sociedade, também há de se defender que a cultura moral comunitária requer seja examinada e controlada pelos próprios membros da comunidade e por observadores externos.

Forçoso reconhecer que uma boa sociedade combina o respeito com os direitos individuais, bem como a satisfação das necessidades básicas dos homens com expectativa de que seus membros vivam com respeito e responsabilidade consigo mesmos, suas famílias, amigos e a comunidade em geral.

Diante deste contexto, é na esfera territorial que as pessoas estabelecem suas relações, e, se reconhecem como pertencentes de uma mesma comunidade, "já que é na "instância da comunidade que os indivíduos edificam suas relações sociais e podem participar de forma mais ativa das decisões políticas. É nesse cenário que se pode estimular a capacidade de autodeterminação do cidadão e de apropriação de sua própria história”. (FOLEY, 2010, p. 139-140).

Seus contornos, porém, ganham maior definição a partir da perspectiva de cada comunidade envolvida, que pautada na informalidade, garante celeridade na prestação "inoficial” da jurisdição, que se converte em satisfação dos interesses materiais das partes envolvidas nas demandas, cujos breves traços se apresentam a seguir.

\section{A MEDIAÇÃO COMUNITÁRIA COMO ESTRATÉGIA DE CIDADANIA PARTICIPATIVA}

Sabe-se que a noção de conflito não é unânime, já que estar em conflito é uma das diversas formas de interação dos indivíduos, sendo que o conflito pode ser compreendido como uma forma evolutiva de estruturação social, bem como um meio potencializador de disputa.

Todas as relações sociais da atualidade experimentam conflitos em determinado momento. Estes conflitos, por uma série de fatores, dentre os quais pode-se citar a distribuição e o desenvolvimento dos papéis sociais, o ritmo frenético imposto pela economia globalizada, a facilidade de comunicação que - paradoxalmente - afasta o seres humanos e faz artificial os laços comunitários, tornaram-se mais complexos do que aqueles existentes há poucas décadas atrás. Desse modo, constata-se que a atual 
complexidade conflitiva é um traço contemporâneo avistado nas esferas mundial e local. (SPENGLER, no prelo).

Estamos vivendo em uma intensa época de reformas e alterações legislativas, esforço que tem o escopo de viabilizar o atendimento do direito constitucional da razoável duração do processo.

De fato o que existe é o empenho em encontrar meios de superação do formalismo exacerbado que constitui a persecução processual. Por certo, o que realmente interessa é o oferecimento de uma jurisdição adequada, célere e eficaz, sem prejuízo as garantias constitucionais.

É nesse contexto que a mediação comunitária aparece como meio de tratamento de conflitos e como possível resposta à incapacidade estatal de oferecer uma jurisdição quantitativa e qualitativamente adequada. A mediação, considerada uma arte, a "arte do compartir" se destina a criar/reatar/fortalecer laços entre os indivíduos, restabelecendo a comunicação, tratando e prevenindo conflitos. (SPENGLER, no prelo).

Destaque-se que é impossível ter paz social sem a paz no judiciário. Desta forma, a mediação de conflitos não pode ser entendida somente como uma forma "alternativa" de resolução de conflitos, mas sim, como a forma "adequada".

É possível reafirmar que as duas últimas décadas do século passado foram as da mediação. Especialmente entre os anos de 1980 e 1990 pôde-se vislumbrar a sua explosão: em todos os lugares falava-se de mediação. O que ocorreu foi a banalização do termo, empregando-o para todo o propósito, a torto e a direito. A função "mediação", não se exprime somente nas relações interpessoais, mas naquelas que cada um pode ter das instituições e, entre outras, com as administrações destas últimas. Assim, não há somente o emprego - bastante intempestivo - do termo "mediação"; existe uma preocupação cada vez mais expressa de encontrar meios para resolver ao problema real: uma enorme dificuldade de se comunicar; dificuldade esta paradoxal numa época em que a mídia experimenta um desenvolvimento extraordinário. (SPENGLER, 2010, p. 316). 
Cumpre ressaltar que a mediação jamais poderá ser judicializada, haja vista que sua "essência" será perdida. Diz-se isso diante do afastamento visível que ela tem do Poder Judiciário, ela não tem ligação com a ociosidade e a repetição. Ademais, tudo que se aproxima do judiciário vai se contaminando.

A mediação de conflitos serve para dissolver aquele sentimento negativo existente nos mediandos. A meta do mediador é conduzir os mediandos à dissolução deste conflito, dando às partes o poder de direcionar seu futuro de maneira clara e livre de mágoas e ressentimentos.

\begin{abstract}
A mediação, enquanto espécie do gênero justiça consensual, poderia ser definida como a forma ecológica de resolução dos conflitos sociais e jurídicos na qual o intuito de satisfação do desejo substitui a aplicação coercitiva e terceirizada de uma sanção legal. Na mediação todos somos iguais enquanto humanos, respeitando as características de cada indivíduo, não sendo possível qualquer espécie de julgamento, as partes não são nominadas como autor - réu vítima - agressor, são denominados como "mediandos". (WARAT, 1998, p. 05).
\end{abstract}

A cooperação faz parte do procedimento no qual se devolve às partes o poder de falar, de escutar, para que eles sejam os atuantes na sessão, que de fato façam alguma coisa para a satisfação de seus interesses. O mediador não está ali para resolver nada, mas sim para fazer com que os mediandos sintam suas emoções e toquem seus corações.

Através deste instituto, busca-se selecionar conflitos mediante a atuação de um terceiro desinteressado. Esse terceiro denomina-se mediador e exerce uma função como que de conselheiro, pois pode aconselhar e sugerir, porém, cabe às partes constituir suas respostas. Com auxílio do mediador, os envolvidos buscarão compreender as fraquezas e as fortalezas de seu problema, a fim de tratar o conflito de forma satisfatória. Na mediação, por constituir um mecanismo consensual, as partes apropriam-se do poder de gerir seus conflitos, diferentemente da Jurisdição estatal tradicional, na qual este poder é delegado aos profissionais do direito, com preponderância àqueles investidos nas funções jurisdicionais. (BOLZAN, 2008, p. 134). 
Nesta esteira de atuação, deve-se tomar o cuidado para não nos fecharmos no academicismo e nos desvincularmos da prática, já que temos a responsabilidade de viver, que pode ser entendida como a responsabilidade social, em que tudo que fizemos deve repercutir em nossas vidas.

Justamente por isso a mediação surge como espaço democrático, uma vez que trabalha com a figura do mediador que, ao invés de se posicionar em local superior às partes, se coloca no meio delas, partilhando de um espaço comum e participativo, voltado para a construção do consenso num pertencer comum. Isso se dá porque a mediação não é uma ciência, mas uma arte na qual o mediador não pode se preocupar em intervir no conflito, oferecendo às partes liberdade para discuti-lo. A mediação, porém, suscita um paradoxo composto pelo fato de dizer ao juiz que não desempenhe o papel que disseram ser seu, isto é, deixar de decidir e adjudicar para propô-la. Conseqüentemente, o que se pede é que pacifique sem decidir, quando seu papel é tradicionalmente o de decidir sem, necessariamente, pacificar. (SPENGLER apud RESTA, p. 320).

A Resolução n. 125 do Conselho Nacional de Justiça fala da função social da mediação, que é dar a sociedade outra forma de resolução dos conflitos, não fazendo qualquer menção a possibilidade de desafogar o judiciário. Ademais, o mediador deve ter formação contínua, no sentido de que cada mediação deve servir para seu crescimento, melhorando sua agenda de trabalho.

Se o escopo é debater um meio compartilhado de administrar e resolver conflitos a mediação comunitária surge como hipótese plausível, forte e bem articulada. Tal se dá porque ela é destinada a criar e fortalecer laços entre os indivíduos, resolvendo e prevenindo conflitos. Essa tarefa tem como fomentador o mediador comunitário que é uma pessoa independente cujo objetivo é levar à comunidade o sentimento de inclusão social através da possibilidade de solução de seus conflitos por ela mesma. A conseqüência é a criação de vínculos e o fortalecimento do sentimento de cidadania e de integração/participação da vida social. (SPENGLER, no prelo). 
Na mediação as partes não devem falar de seus direitos, e sim de suas necessidades, o mediador não resolve nada, ele atende as pessoas, não se projeta o passado, mas o futuro, não se fala de dependência, mas de emancipação, aqui o linguajar processual fica somente na regularização dos termos do acordo, dando as partes o reconhecimento de suas expressões. Não se busca a justiça e sim a satisfação pessoal dos mediandos.

Segundo Warat (2004, p. 67):

A mediação é:

A inscrição do amor no conflito

Uma forma de realização da autonomia

Uma possibilidade de crescimento interior através dos conflitos

Um modo de transformação dos conflitos a partir das próprias identidades

Uma prática dos conflitos sustentada pela compaixão e pela sensibilidade

Um paradigma cultural e um paradigma específico do Direito

Um modo particular de terapia

Uma nova visão da cidadania, dos direitos humanos e da democracia.

Por fim, pode-se concluir que a Resolução n. 125, do Conselho Nacional de Justiça tem como principais objetivos a adequada formação dos mediadores, a responsabilidade social e a pacificação da sociedade como um todo.

Diante destas circunstâncias, visível a

desregulação estatal e os indícios deste fenômeno são evidentes: o crescimento dos mercados mundiais, a globalização e sua instituições impondo as políticas públicas aos Estados dos países endividados, as privatizações sem qualquer controle ou participação democrática. Esta retração do Estado privatiza alguns temas de interesse público, minando a base do pilar emancipação. A crise econômica de âmbito mundial, que eclodiu em outubro de 2008, revela as consequiências da opção pela centralidade da lógica de mercado. (FOLEY, 2010, p. 4041).

Por conseguinte, 
a aspiração por políticas públicas controladas pelo conjunto da cidadania sucumbiu mediante a apropriação do espaço público pelos interesses privados de minorias. Visto por uma lente unilateral, tal fenômeno poderia representar o triunfo deste modelo de capitalismo e a consolidação da privatização das relações sociais. (FOLEY, 2010, p. 41).

É visível que a sociedade não pode mais contar tão somente com o auxílio da justiça estatal para usufruir e contar com os serviços públicos, tendo em vista a realidade contemporânea, plural e fragmentada em que se vive, que exige cada vez mais uma concepção de Direito que se adeqüe a estas características.

Uma das restrições dos comunitários em relação ao enfoque liberal é a de que os indivíduos não podem ser considerados descolados de seus fins, valores e concepções de bem, todos construídos na relação com a comunidade. Diante do pluralismo, não há um ponto de vista universal válido para todas as sociedades. Uma concepção de justiça deve convergir em um acordo ético, permeado, porém, pela tradição e por valores compartilhados. O consenso, pois, será sempre conflitivo e parcial. (FOLEY, 2010, p. 47).

Fica, pois, claro que no tocante à realização da Justiça, a mediação comunitária é capaz de oferecer uma justiça cidadã, alterandose a visão negativa que se tem acerca do conflito, com fundamento da alteridade e na percepção do todo. Ademais, é possível, a partir da mediação, desenvolver o senso no ser humano de que ele faz parte de um contexto maior, bem como que é capaz de reconhecer seus direitos e deveres, chegando, por conseguinte, à resolução dos conflitos.

Diferentemente do magistrado que possui a legitimação estatal/burocrática para tratar conflitos, o mediador comunitário possui uma legitimidade baseada na sua conduta e nos seus valores pessoais cuja principal consequiência é inspirar nos conflitantes a certeza de que seus problemas são tratados por um igual. Assim, os conflitos endereçados a mediação comunitária contam com a presença de um terceiro que conhece a realidade, os valores e os hábitos dos conflitantes. Fala a mesma linguagem que eles e possui uma legitimidade que não é atribuída pelo Estado e sim pelas próprias partes, em função 
de suas características, da sua conduta, do seu código de ética e de moral. (SPENGLER, no prelo).

Sob este prisma, a jurisdição, enquanto modelo estatal regulatório é necessária à manutenção da ordem, até porque não pode ser encarada como única possibilidade de resolução de conflitos. Contudo, é preciso que se reconheça que o monopólio da jurisdição deve ceder espaço às alterações promovidas por métodos adequados de resolução dos conflitos, para que se "devolva" à comunidade, parte desta competência, nos espaços onde os cidadãos constroem suas relações.

No tocante a justiça,

para os comunitários é algo efêmero que pode assumir formas distintas, a depender das diferentes esferas nas quais ela opera. Nesse sentido, a distribuição de bens não ocorre por meio de um padrão universalmente compartilhado. A justiça está, pois, fragmentada em um sistema em que cada bem pertence a uma esfera, uma categoria distributiva regida por critérios próprios. (FOLEY, 2010, p. 48).

De fato, a solidariedade é inserida no diálogo, sendo que as pessoas discutem seus problemas e o conflito deixa de ser algo negativo, que afasta as pessoas, e passa a ser algo pelo qual as pessoas lutam para mudar.

Ao contrário dos ritos da justiça instituída pelo Estado, que se mostra aos olhos dos membros da sociedade como lenta, burocrática, sem humanidade, a mediação comunitária promove a participação direta da comunidade, resgatando e valorizando o perfil do mediador, bem como o poder de voz dos mediandos.

Por certo que a mediação comunitária é alvo de críticas ${ }^{3}$,

\footnotetext{
${ }^{3}$ Para alguns de seus críticos, “a mediação comunitária é um serviço destinado àqueles que não têm acesso às cortes. Trata-se, portanto, de uma justiça de segunda classe, pela qual os temas que são essencialmente de ordem pública são privatizados. Nesse sentido, a resolução das disputas pela comunidade representa uma extensão do controle do Estado sobre a esfera privada dos indivíduos. A mediação perpetua a má distribuição dos poderes político e econômico, na medida em que desconsidera as diferenças entre disputantes entregando-os "carneiros aos leões". A crítica de que o processo de mediação é alienante porque oculta as verdadeiras raízes estruturais do conflito não procede (...). É que, a depender da condução do processo judicial, este também pode vir a ser alienante: a parte não participa das discussões jurídicas, eis que reservadas aos chamados "operadores do direito" - tampouco compreende os direitos que está a
} 
em resumo as críticas convergem em um mesmo sentido e revelam uma concepção marxista-ortodoxa, pela qual o Estado burguês é um mero instrumento de dominação de uma classe sobre a outra. Basicamente, os seus autores afirmam que a proposta é uma máscara ideológica, na medida em que obscurece as verdadeiras raízes estruturais dos conflitos sociais, os quais são tratados com soluções superficiais e individuais. Ademais, sustentam, os membros da comunidade preferem as decisões advindas das cortes porque elas compensam as desigualdades de poder entre os litigantes. Assim, a justiça comunitária é apenas uma forma nova e sutil de garantir a manutenção do status quo, por meio da regulação estatal. (FOLEY, 2010, p. 89).

É por isso que novos mecanismos estão sendo utilizados como forma autêntica e democrática na resolução de litígios. A mediação fomenta a participação dos cidadãos na tomada de decisões, facilita o acesso à justiça, como também promove a responsabilização dos sujeitos e auxilia o diálogo assertivo.

A justiça comunitária é uma aposta diferente que não tem por base códigos, regras escritas/positivadas e o poder/legitimidade do Judiciário e de seus magistrados. Sem deixar de reconhecer a importância de tais instituições e de seus profissionais, a justiça comunitária aposta na amizade como meio de garantir à comunidade autonomia e responsabilidade para tratar seus conflitos com o auxílio de um terceiro, igual, legitimado por suas características morais e por seus vínculos, não institucionais, mas de amizade...(SPENGLER, no prelo).

Portanto, a mediação é uma prática emancipatória na medida em que revela no cidadão a capacidade que o mesmo possui de, por si só, reconhecer direitos e deveres e administrá-los.

pleitear e menos ainda, aprende a lidar com futuros conflitos da mesma natureza. A mediação, uma vez direcionada à compreensão e reflexão sobre as causas e as circunstancias do conflito, pode-se revelar extremamente pedagógica e emancipatória, a depender da perspectiva que se adote. (FOLEY, 2010, p. 90-93). 
Desta forma, coloca os mediandos como co-responsáveis pelo conflito existente, e pela harmonia coletiva, devolvendo a noção e a responsabilidade de que são atores de suas próprias vidas e de que fazem parte de uma coletividade, fomentando a participação social.

Os programas de justiça comunitária procuram desenvolver essas pretensões, transformando as comunidades fragmentadas em espaços abertos para o diálogo e o desenvolvimento da autodeterminação, da solidariedade e da paz, portanto, imprescindível a análise dos traços impressos nos agrupamentos humanos unidos por uma identidade territorial, que confere à comunidade o status de locus. (FOLEY, 2010, p. 139).

\section{CONSIDERAÇÕES FINAIS}

É visível que a sociedade não pode mais contar tão somente com o auxílio da justiça estatal, tendo em vista a realidade contemporânea, plural e fragmentada em que se vive, que exige cada vez mais uma concepção de Direito que se adequie a estas características.

No tocante à realização da Justiça, a mediação comunitária é capaz de oferecer uma justiça cidadã, alterando-se a visão negativa que se tem acerca do conflito, com fundamento da alteridade e na percepção do todo. Ademais, é possível, a partir da mediação, desenvolver o senso no ser humano de que ele faz parte de um contexto maior, bem como que é capaz de reconhecer seus direitos e deveres, chegando, por conseguinte, à resolução dos conflitos.

Sob este prisma, a jurisdição, enquanto modelo estatal regulatório é necessária à manutenção da ordem, contudo não pode ser encarada como única possibilidade de resolução de conflitos. Desta forma, é preciso que se reconheça que o monopólio da jurisdição deve ceder espaço às alterações promovidas por métodos adequados de resolução dos conflitos, para que se "devolva" à comunidade, parte desta competência, nos espaços onde os cidadãos constroem suas relações.

De fato, a solidariedade é inserida no diálogo, sendo que as pessoas discutem seus problemas e o conflito deixa de ser algo negativo, que afasta as pessoas, e passa a ser algo pelo qual as pessoas lutam para mudar.

Ao contrário dos ritos da justiça instituída pelo Estado, que se mostra aos olhos dos membros da sociedade como lenta, burocrática, sem humanidade, a mediação comunitária promove a participação direta da 
comunidade, resgatando e valorizando o perfil cidadão, bem como o poder de voz da comunidade.

É por isso que novos mecanismos estão sendo utilizados como forma autêntica e democrática na resolução de litígios. A mediação fomenta a participação dos cidadãos na tomada de decisões, facilita o acesso à justiça, como também promove a responsabilização dos sujeitos e auxilia o diálogo assertivo.

Portanto, a mediação é uma prática emancipatória na medida em que revela no cidadão a capacidade que o mesmo possui de, por si só, reconhecer direitos e deveres e administrá-los.

Desta forma, coloca os mediandos como co-responsáveis pelo conflito existente e pela harmonia coletiva, devolvendo a noção e a responsabilidade de que são atores de suas próprias vidas e de que fazem parte de uma coletividade, fomentando, em suma, os contornos da cidadania plena.

\section{REFERÊNCIAS}

ARENDT, Hannah. As Origens do Totalitarismo. Editora Companhia das Letras, São Paulo: 2004.

BAUMAN, Zygmunt. Modernidade e Holocausto. Trad: Marcus Penchel. Rio de Janeiro: Zahar, 1998.

BERTASO, João Martins. Cidadania e Interculturalidade. Santo Angelo: FURI, 2010.

BOBBIO, Norberto. A Era dos Direitos. Rio de Janeiro: Elsevier, 2004.

BOLZAN DE MORAIS, José de Luis. Crise(s) da jurisdição e acesso à justiça: uma questão recorrente. IN: SPENGLER, F; CESAR LUCAS, D. Conflito, jurisdição e direitos humanos: (Des) apontamentos sobre o novo cenário social. Ijuí: Ed. Edunisc, 2008.

BOLZAN DE MORAIS, José Luis. Mediação e arbitragem: alternativas à jurisdição. 2 Ed. Porto Alegre: Livraria do Advogado, 2008. 
COVRE, Maria de Lourdes Manzini. O que é cidadania. São Paulo: Brasiliense, 2007.

ETZIONI, Amitai. La tercera vía hacia uma buena sociedad.

Propuestas desde el comunitarismo. Prólogo de José Pérez Adán. Madri:

Editorial Trotta, 2001.

FOLEY, Glaucia Falsarella. Justiça Comunitária: por uma justiça da emancipação. Belo Horizonte: Fórum, 2010.

FOUCAULT, Michel. Microfísica do poder. Organização, introdução e Revisão Técnica de Roberto Machado.

GUIDDENS, Anthony. A terceira via: reflexões sobre o impasse político atual e o futuro da social democracia. Rio de janeiro: Record, 1999.

LAFER, Celso. A reconstrução dos Direitos Humanos. São Paulo: Companhia das Letras, 1991.

LOCKE, John. Segundo Tratado do Governo Civil. Tradução: Magda Lopes e Marisa Lobo da Costa. Editora Vozes: 2006.

MARTÍNEZ, Alejandro Rosillo.( et.al. ). Teoria Crítica dos direitos humanos no século XXI. Porto Alegre: EDIPUCRS, 2008.

MARX, Karl, Engels, Friedrich. Manifesto do partido comunista. Instituto José Luiz e Rosa Sundermann, 2003.

NEVES, Marcelo. Entre Têmis e o Leviatã: uma relação difícil: o Estado democrático de direito a partir e além de Luhmann e Habermas. E ed. São Paulo: Martins Fontes, 2008.

SANTOS, Boaventura de Sousa. Para uma revolução democrática da justiça. São Paulo: Cortez, 2007.

SPENGLER, Fabiana. Da jurisdição à mediação: por uma outra cultura no tratamento de conflitos. Ijuí: Ed: Unijuí, 2010. 
. A mediação e o mediador comunitários: a resolução dos conflitos em um espaço comunitário não estatal. No prelo.

VIEIRA, Liszt. Cidadania e globalização. $6^{\text {a }}$ ed. Rio de Janeiro: Record, 2002.

Os argonautas da cidadania. Rio de Janeiro: Record, 2001.

WACQUANT, Loic. Castigar a los pobres: El govierno neoliberal de la inseguridad social. Barcelona: Gedisa, 2009.

WEBER, Max. Economia y sociedade. México. Ed. Fondo de Cultura Economico, 1964. 